\title{
Multiple crack detection using wavelet transforms and energy signal techniques
}

\author{
Jalal Akbari* \\ Bu-Ali Sina University, Department of Civil Engineering, Hamedan, Iran, \\ j.akbari@basu.ac.ir, bttps://orcid.org/0000-0001-9713-8652
}

Majid Ahmadifarid

Laboratory of Earthquake Engineering and Structural Health Monitoring of Infrastructures (LEESHMI), Bu-Ali Sina University, Hamedan, Iran,

mabmadifarid@gmail.com

\author{
Abbas Kazemi Amiri \\ Wind Energy and Control Centre, Department of Electric \& Electronic Engineering, University of Strathclyde, Glasgow, UK \\ abbas.kazemi-amiri@strath.ac.uk
}

\section{ABSTRACT.}

Wavelet transforms are efficient tools for structural health monitoring (SHM) and damage detection. However, these methods are encountered with some limitations in practice. Thus, signal energy analysis is used as an alternative technique for damage detection. In this paper, discrete wavelet transforms (DW'T) and Teager energy operator (TEO) is applied to the curvature of the mode shapes of the beams, and the locations of the damages are identified. The results show that in comparison with the discrete wavelet transform, the signal energy operator has better performance. This superiority in detecting the damages, especially near the supports of the beam, is obvious and has enough sensitivities in low damage intensities. Additionally, the damage detection in the cases that the response data are noisy is investigated. For this purpose, by adding low-intensity noises to the curvature of the mode shapes, the abilities of the mentioned methods are evaluated. The results indicate that each method is not individually efficient in the detection of damages in noisy conditions, but the combination of them under noisy conditions is more reliable.

KEYWORDS. Multiple crack detection, Wavelet transforms, Signal energy, Mode shape curvature.

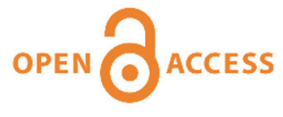

Citation: Akbari, J., Ahmadifarid, M., Kazemi Amiri, A., Multiple crack detection using wavelet transforms and energy signal techniques, Frattura ed Integrità Strutturale, 52 (2020) 269-280.

Received: 13.01 .2020

Accepted: 03.03 .2020

Published: 01.04.2020

Copyright: (C) 2020 This is an open access article under the terms of the CC-BY 4.0, which permits unrestricted use, distribution, and reproduction in any medium, provided the original author and source are credited. 


\section{INTRODUCTION}

$\mathrm{I}$ $\mathrm{n}$ recent years, structural damage detection is an interesting field for the researchers. From a practical point of view, proposing an effective non-destructive technique is a crucial task to maintain the safety and integrity of the structures. The previous studies [1] have reported that most of the non-destructive techniques could be categorized as local or global damage identification methods. Furthermore, with increasing the size and dimensions of the buildings or structural elements, the capabilities of traditional damage detection methods such as ultra-Sonic and X-ray tests or Schmidt's hammer are not practically possible. Because such methods require easy accessibility for testing and knowing the vicinity of the damage, which cannot be guaranteed in most cases in civil or mechanical engineering. As well, the health monitoring of large-scale structures is a time-consuming and costly process.

The vibration-based damage identification method as a global technique is developed to overcome these difficulties. The main idea for vibration-based damage identification is that the damage-induced changes in the physical properties such as mass, damping, and stiffness will lead to detectable changes in natural frequencies, modal damping, and mode shapes.

Therefore, with the appearance of modern computer facilities and digital signal processing techniques, new research on SHM has seriously been started. Ratcliffe [2] presented a structural health monitoring method that could identify the damage without requiring the modal data of the intact structure. He utilized the curve-fitting technique of mode shape's curvature in one-dimensional beams. In this discipline, Weng and Deng [3] used the wavelet transforms for the detection of small transverse cracks in static and dynamic loadings for pinned-pinned and clamped-free beams. Hou et. al. [4] examined wavelet capabilities for damage detection for a system with the mass and spring as a single degree of freedom model. They claimed that the wavelet has enough capability to identify the time of yielding of spring. Chang and Chen [5] conducted research on the Timoshenko beam based on wavelet distance. The proposed wavelet successfully recognized the damage on beams using the first and second mode shapes. Ovanesova and Suarez [6] utilized stationary discrete wavelet for detecting damages in beam and frame type structures. Loutridis et al. [7] carried- out the research for the detection of a crack in double beams using continuous wavelet transforms. Chang and Chen [8] studied a cantilever-type beam that the crack was an open crack that has been modeled using torsional spring. In their research, Gabor wavelet has been applied to the mode shapes, in order to find the crack location.

Gökdağ, H., \& Kopmaz, O [9] conducted the research for identifying crack on beams by a combination of the continuous and discrete wavelet. In their research, the combination of the mode shapes of an intact and damaged beam has been taken into account under the errors of measurement and local damage. Ruka [10] studied the effects of higher modes in system identification utilizing discrete wavelet and showed that applying higher modes will result in better performance.

Zhong and Oyadiji [11] considered the modal responses of damaged beams using the finite-element method and experimental data. The results showed that the discrete wavelet when the sampling rate is high could not obviously detect the details of the synthesized signal. In addition, in further research, Zhang and Oyadji [12] considered the reconstructed mode shapes for damaged beams using a discrete wavelet method. They could identify the damage with a $4 \%$ intensity for hinged support beams.

Algaba et al. [13] defined a new damage index composed of natural frequency and mode shape for damage detection using continuous wavelet. The proposed method could not be able to identify low damages. Therefore, Solís et.al [14] developed a new damage index for low damages with $5 \%$ and $10 \%$ intensities. However, both indexes were not able to identify the damages for noisy conditions.

Khorram et.al [15] implemented continuous wavelet and factorial texting techniques for the detection of multiple damages on beams. Cao.M, et.al [16-17] studied the damage detection for noisy data. In their research, the mode shape curvature polluted by noise with a given signal to noise ratio. When the wavelet transforms are not able to identify the damage, a combination of wavelet and Teager energy of signal could identify the damages with the intensity of $5 \%$. Akbari and Ahmadifarid [18] applied the discrete wavelet transform and energy operator for damage detection of the two-dimensional frames. There are two main reasons for the study on damage detection of simple structures like beams: (1) most of the structures or their major components in civil and mechanical engineering could be simplified as a beam or plate.

(2) the problem of identifying specific damage in a beam/plate provides an important benchmark for the effectiveness and accuracy of the identification techniques. Therefore, in this paper, the damage identification of beam structures in different support conditions and also various damage scenarios have been carefully investigated.

To the knowledge of the authors, multiple cracks usually cause damages with low intensity, which are difficult to be detected. This could be much more difficult when the damage is close to the supports. The authors believe that damage identification in such cases has not received enough attention and comprehensive studies in this regard is required. Therefore, this paper focuses on the evaluation of multiple cracks detection near the supports of the beams. 
For this purpose, the mathematical models of two-beam structures with different boundary conditions, including pinedpined and clamped-clamped, were established in MATLAB [19] by the finite-element modeling, using Bernoulli beam elements. Two different signal-processing techniques are employed for crack location detection in different damage scenarios by application of mode shape curvature in the absence and presence of noise in the data.

\section{Signal Processing Techniques}

I $\mathrm{n}$ this paper damage detection of beams with different boundary conditions using discrete wavelet transforms (DWT), Teager-energy operator (TEO) and the combination of them have been explored. The reason for applying the mentioned methods is due to the capabilities of the methods for damage detection, especially in the presence of noisy conditions.

\section{Discrete W avelet Transforms (DWT)}

Wavelet functions are composed of basis functions that have the capability of synthesizing the signal in time (location) and frequency (scale) domain. In wavelet analysis, the mother wavelet function is defined as Eqn. (1)

$$
\psi_{\mathrm{a}, \mathrm{b}}(\mathrm{t})=\frac{1}{\sqrt{\mathrm{a}}} \psi\left(\frac{\mathrm{t}-\mathrm{b}}{\mathrm{a}}\right)
$$

Mother wavelet in addition to time $\mathrm{t}$, is described with a,b parameters in which they are the scaling and transformation parameters, respectively. Transformation of continuous wavelet for an arbitrary function, $f(t)$, is written as Eqn.(2)

$$
\operatorname{CWT}(a, b)=\frac{1}{\sqrt{a}} \int f(t) \cdot \psi^{*}\left(\frac{t-b}{a}\right) d t
$$

where $\mathrm{a}=2^{\mathrm{J}}, \mathrm{b}=2^{\mathrm{J}} \mathrm{k}$. Parameters $\mathrm{J}, \mathrm{k}$ are the indexes of the synthesizing level of an arbitrary signal. By substitution of these parameters in Eqn.(2), Eqn.(3) could be written as follows.

$$
\operatorname{DWT}(J, k)=2^{\frac{-J}{2}} \int_{-\infty}^{+\infty} f(t) \cdot \psi^{*}\left(2^{-J} t-k\right) d t
$$

According to Eqn.(3), two types of filter is imposed on the signal. The first one is low- pass filter imparted as a scaling function or father wavelet that shows the approximation of a signal, and the second one is a high-pass frequency filter that accounts for the signal components in the higher frequencies (signal details). The coefficients of approximation and details are calculated as Eqn.(4)

$$
\begin{aligned}
& \mathrm{cA}_{\mathrm{j}}(\mathrm{k})=\int_{-\infty}^{+\infty} \mathrm{f}(\mathrm{t}) \theta(\mathrm{x}) \mathrm{dx}, \\
& \mathrm{cD}_{\mathrm{j}}(\mathrm{k})=\int_{-\infty}^{+\infty} \mathrm{f}(\mathrm{t}) \psi(\mathrm{x}) \mathrm{dx}
\end{aligned}
$$

where $\theta(x)$ is the scaling function or the father wavelet and $\psi(x)$ is a mother wavelet [20]. The relation between mother and father wavelets could be written as Eqn.(5)

$$
\psi(x)=(-1)^{m} \frac{d^{m} \theta(x)}{d x^{m}}
$$

In this paper, for signal processing and damage detection, the Daubechies and Symlet wavelets [19] with different scaling have been implemented. 
Teager -Kayser Energy Operator (TEO)

The free vibration response of the single degree of freedom (SDF) system with concentrated mass $m$ and stiffness $k$ is written as Eqn.(6)

$$
x(t)=A \cos (\omega t+\theta)
$$

where, $x(t)$ is the time variable position of the mass, $A$ is the peak amplitude of the vibration, $\omega$ refers to the natural frequency of vibration and $\theta$ is the phase angle of the free vibration. For the mentioned SDF system, the total energy is computed as Eqn.(7)

$$
\mathrm{E}(\mathrm{t})=\frac{1}{2} \mathrm{kx} \mathrm{x}^{2}+\frac{1}{2} \mathrm{mv}^{2} \rightarrow \mathrm{E}=\frac{1}{2} \mathrm{~m} \omega^{2} \mathrm{~A}^{2}
$$

This equation indicates that the energy of a system is dependent on the frequency and amplitude of the vibration. For a discrete signal, the free-response could be written as Eqn.(8)

$$
\mathrm{x}_{\mathrm{n}}=\mathrm{A} \cos (\Omega \mathrm{n}+\Phi) \rightarrow\left\{\begin{array}{l}
\mathrm{x}_{\mathrm{n}-1}=\operatorname{Acos}(\Omega(\mathrm{n}-1)+\Phi) \\
\mathrm{x}_{\mathrm{n}+1}=\operatorname{Acos}(\Omega(\mathrm{n}+1)+\Phi)
\end{array}\right\}
$$

where $\Omega$ refers to the natural frequency of the system and $\Phi$ is the phase angle of the vibration. After processing and simplifying the above equation, the following equation could be obtained as Eqn.(9)

$$
A^{2} \sin ^{2}(\Omega)=x_{n}^{2}-x_{n-1} x_{n+1}
$$

Then, Teager- Kayser operator for a discrete signal $x_{n}$ is defined using $\Psi$ and could be present as Eqn.(10)

$$
\Psi\left[\mathrm{x}_{\mathrm{n}}\right]=\mathrm{x}_{\mathrm{n}}^{2}-\mathrm{x}_{\mathrm{n}-1} \mathrm{x}_{\mathrm{n}+1} .
$$

\section{Problem Definition}

T $\mathrm{n}$ this paper, the single and multiple damage detection for the beam-type structures with pined-pined and clampedclamped boundary conditions were investigated. For the steel beams as depicted in Fig. 1 the geometrical and mechanical specifications are presented at Tab.1

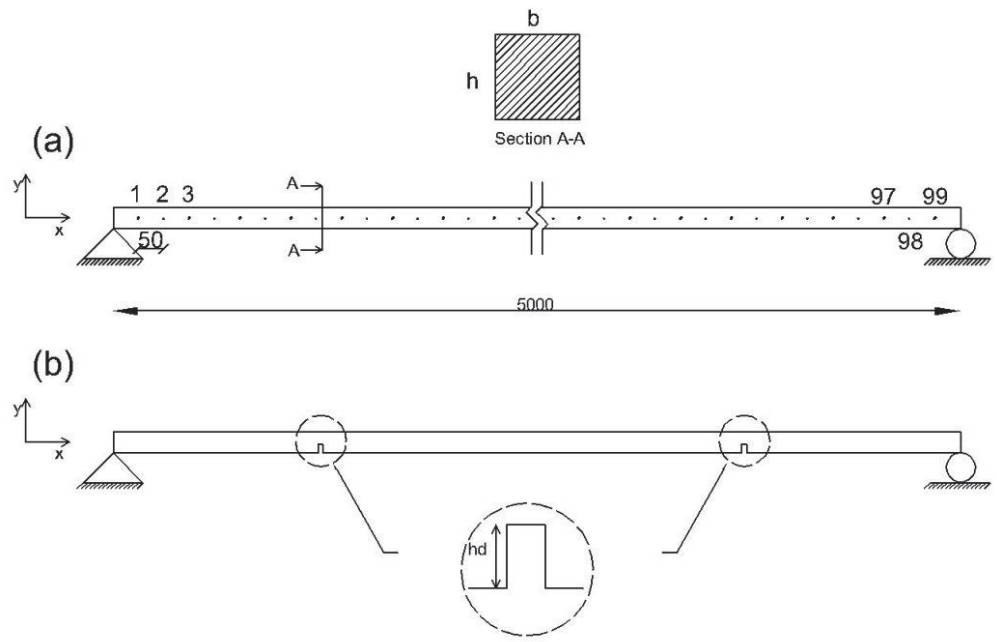

Figure 1: The schematic figure of the studied beams (a), and the schematic locations of multiple damages (b). 


\begin{tabular}{ccccc}
\hline Length $(\mathrm{m})$ & $\mathrm{b}(\mathrm{mm})$ & $\mathrm{h}(\mathrm{mm})$ & $\varrho\left(\mathrm{kg} / \mathrm{m}^{3}\right)$ & $\mathrm{E}(\mathrm{GPa})$ \\
5.0 & 100 & 50 & 7850 & 210 \\
\hline
\end{tabular}

Table 1: Mechanical and geometrical specifications of the studied beams.

For finite element modeling, the beam length is evenly divided into 100 elements. Thus, the length of each element is $50 \mathrm{~mm}$. The modal information of the beams has been extracted from a finite - element modeling of each beam.

In order to simulate the damaged finite element model, the height of the damaged element is reduced to $0.95 \mathrm{~h} \mathrm{e.g.} \mathrm{h}_{\mathrm{d}}=0.95 \mathrm{~h}$ for $5 \%$ damage. The modal curvature of the beam $\left(\Phi^{\prime \prime}\right)$ is calculated using the central finite difference method as Eqn.(11).

$$
\Phi^{\prime \prime}=\frac{\Phi(\mathrm{L}-\Delta \mathrm{L})-2 \Phi(\mathrm{L})+\Phi(\mathrm{L}+\Delta \mathrm{L})}{(\Delta \mathrm{L})^{2}}
$$

where, $\Phi, \Phi^{\prime \prime}$ are the mode shapes and the curvature of mode shapes, respectively. As well, $L$ refers to the length of the beam. Here, for studying of the damage detection in the noisy conditions, the signal to noise ratio (SNR) is defined. This ratio is introduced as the ratio of the power of the input signal without any pollution, to the power of the white noise signal. This ratio is a criterion for comparing the desirability of a signal to the noise and is defined as Eqn.(12)

$$
\mathrm{SNR}_{\mathrm{db}}=10 \log _{10}\left(\frac{\mathrm{P}_{\text {signal }}}{\mathrm{P}_{\text {noise }}}\right)
$$

where, $\mathrm{P}_{\text {signal }}, \mathrm{P}_{\text {noise }}$ are the power of the signal and the power of noise, respectively. The higher values of SNR for a signal indicates the lower contamination of the signal. In this paper, SNR is set to 75,65 and $55 \mathrm{~dB}$ for providing the noisy data.

\begin{tabular}{cccccc}
\hline $\begin{array}{c}\text { Scenario } \\
\text { no. }\end{array}$ & $\begin{array}{c}\text { Support } \\
\text { condition }\end{array}$ & $\begin{array}{c}\text { No. of } \\
\text { damaged } \\
\text { elements }\end{array}$ & $\begin{array}{c}\text { Damage } \\
\text { Intensity }(\%)\end{array}$ & $\begin{array}{c}\text { Order of mode } \\
\text { shape in signal } \\
\text { energy }\end{array}$ & $\begin{array}{c}\text { Order of mode } \\
\text { shape in } \\
\text { wavelet }\end{array}$ \\
1 & Pined-Pined & $20,30,80$ & $5,5,5$ & 1 & 4 \\
2 & Pined-Pined & $48,51,54$ & $5,5,5$ & 1 & 3 \\
3 & Pined-Pined & 5,95 & 5,5 & 3 & 1 \\
4 & Pined-Pined & 1,99 & 5,5 & 6 & 1 \\
5 & Pined-Pined & $20,50,80$ & $10,10,10$ & 1 & 3 \\
6 & Pined-Pined & $20,50,80$ & $5,10,15$ & 1 & 3 \\
7 & Clamped-Clamped & $10,20,90$ & $5,5,5$ & 5 & 3 \\
8 & Clamped-Clamped & $20,23,26$ & $5,5,5$ & 3 & 3 \\
9 & Clamped-Clamped & $30,45,80$ & $5,10,15$ & 3 & 3 \\
\hline
\end{tabular}

Table 2: The proposed scenarios of damage detection on beams without noisy conditions.

\section{Results without noisy data}

In this section, damage detection for multiple- damage detection for pined-pined and clamped-clamped boundary conditions has been presented. For this purpose, several scenarios with and without noisy conditions have been designated. Firstly, the modal data for intact and damaged beams are extracted, and then the discrete wavelet is imposed on the mode shapes using MATLAB functions [18]. Secondly, using Eqn.(4) the coefficients of discrete wavelets are obtained, and employing Eqn.(10), the energy of the signal is obtained. In Tab. 2, the designed scenarios for damage detection without noise on the beams have been presented. 
Fig. 2 illustrates the damage detection results corresponding to the scenarios No. 1. In Figs. a and c the signal energy method has been successfully identified with the damaged elements with clear knobs. This method can identify the multiple damaged elements with a distance of the elements equal to $15 \mathrm{~cm}$. However, as can be seen from graphs b and d, the wavelet transform did not succeed in the detection of the damages with a low intensity equal to $5 \%$.
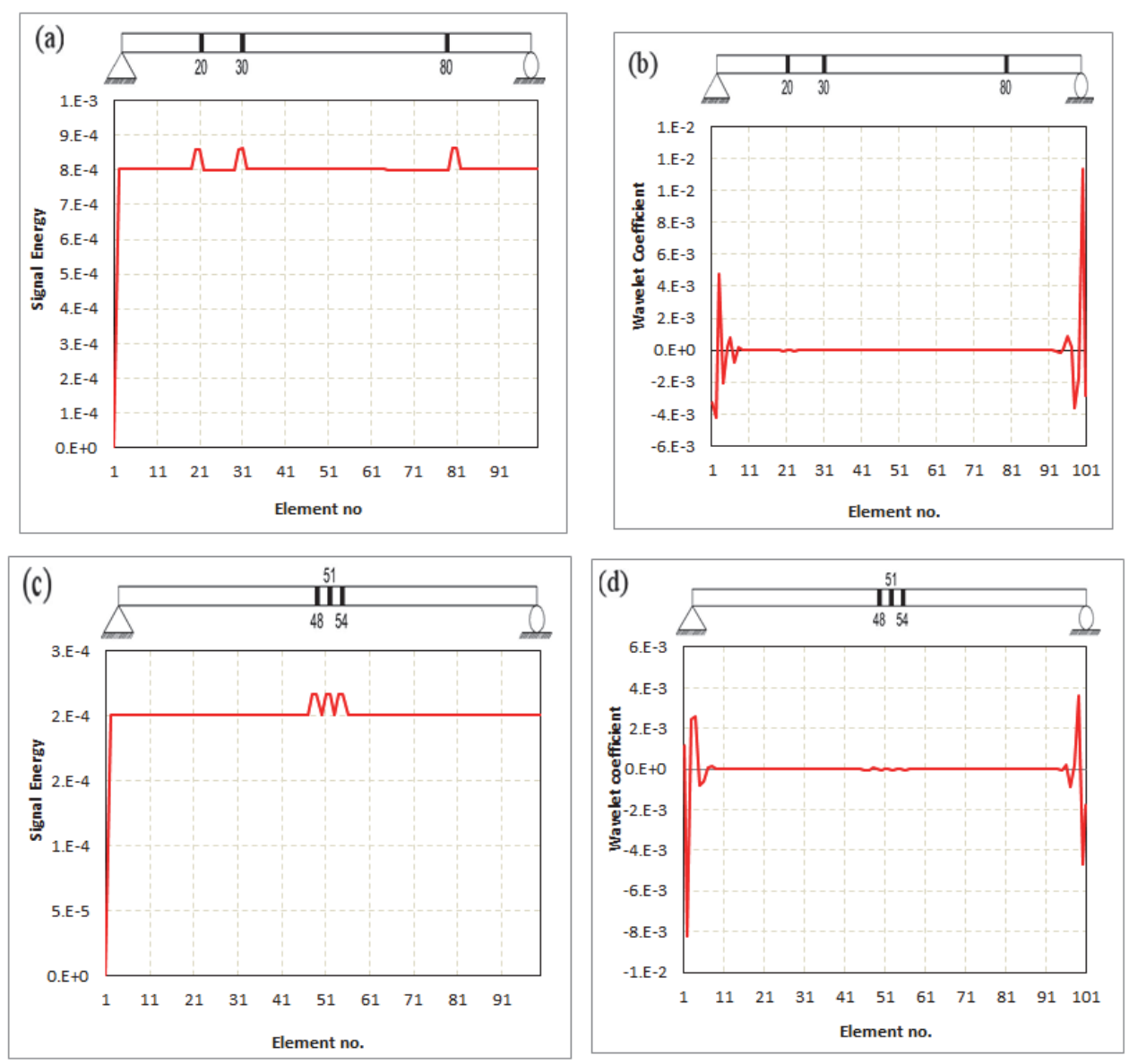

Figure 2: Damage detection using signal energy (a,c) and wavelet (b,d) for scenarios 1,2.

According to graphs b,d in Fig. 2, in the wavelet method, the disorders (irregularities) in two ends of the support of the beams are observed. Therefore this dilemma makes damage detection a difficult task. In order to overcome this problem, the mode shape has been extended from both ends of the beams. For this purpose, from each side of the supports, 50 elements have been artificially added to the finite - element model, and the results are depicted in Fig. 3.
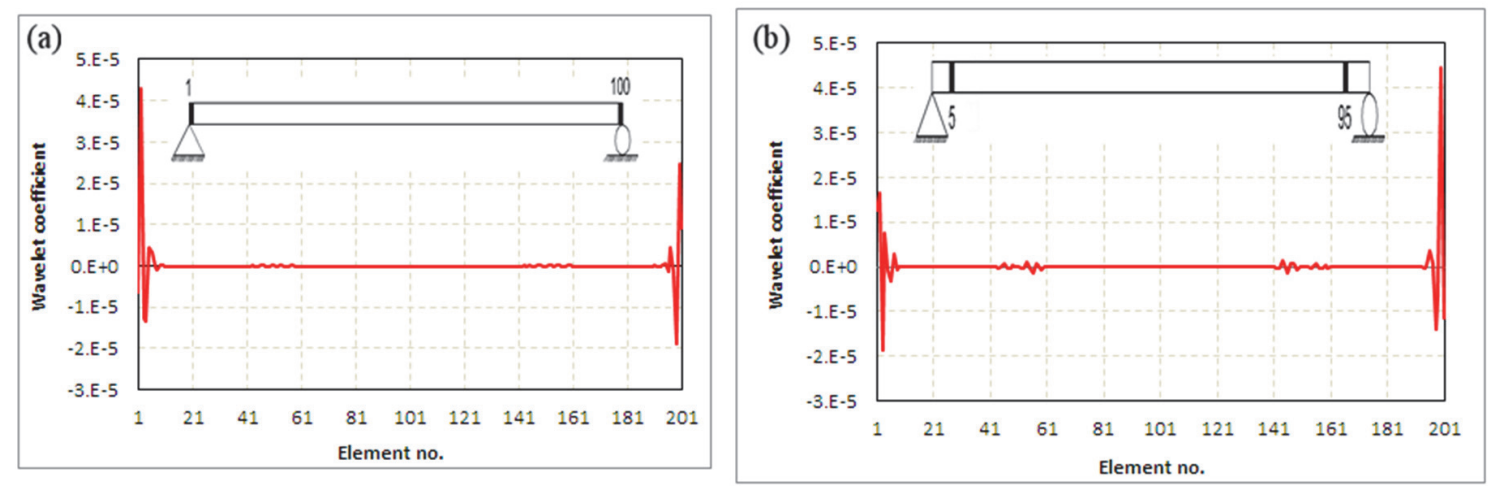

Figure 3: Damage detection using wavelet for scenario no.3. Damages in elements 1 and 100 (a), and Damages in elements 5 and 95 (b). 
As illustrated in Fig. 3, compared to the energy method, wavelet transforms are very sensitive with respect to the starting position of extension and disorders have been appeared in these positions, and this drawback made the damage detection impossible. Additionally, the performance of the first mode shape was better in comparison with the use of higher mode shapes. In other words, when the higher mode shapes have been used for finding the locations of damaged elements, negligible knobs or disorders have been seen. Therefore, by these small disorders, detections were not possible.

As depicted in Fig. 4, signal energy could successfully detect the damages near the supports of the pined-pined beams, while the fictitious mode shape extension from the end of the beams is unnecessary.
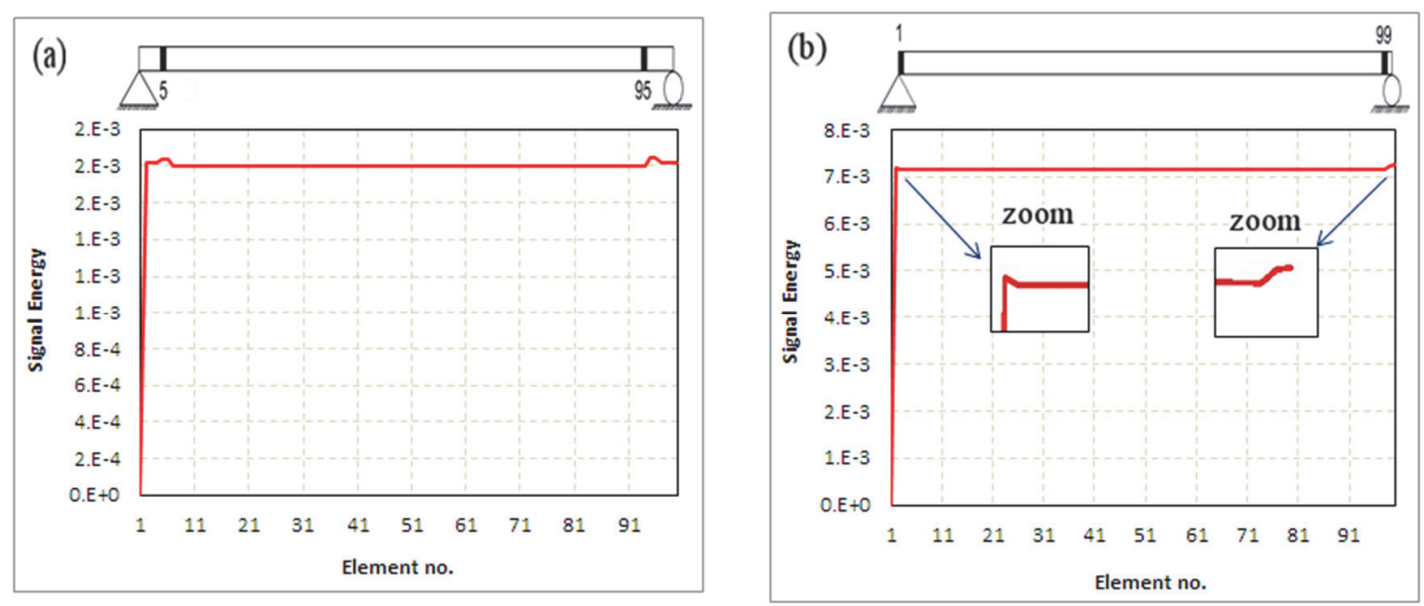

Figure 4: Damage detection using signal energy for scenario no.3 and no.4. Damages in elements 5 and 95 (a), and Damages in elements 1 and 99 (b).

Fig. 5 presents the abilities and sensitivities of the defined methods for different values of the damage intensities. Signal energy could detect damage for various intensities of damaged elements with specified knobs in the graph (a). However, in the wavelet method, all of the intensities are the same which is not a good sign for this method.
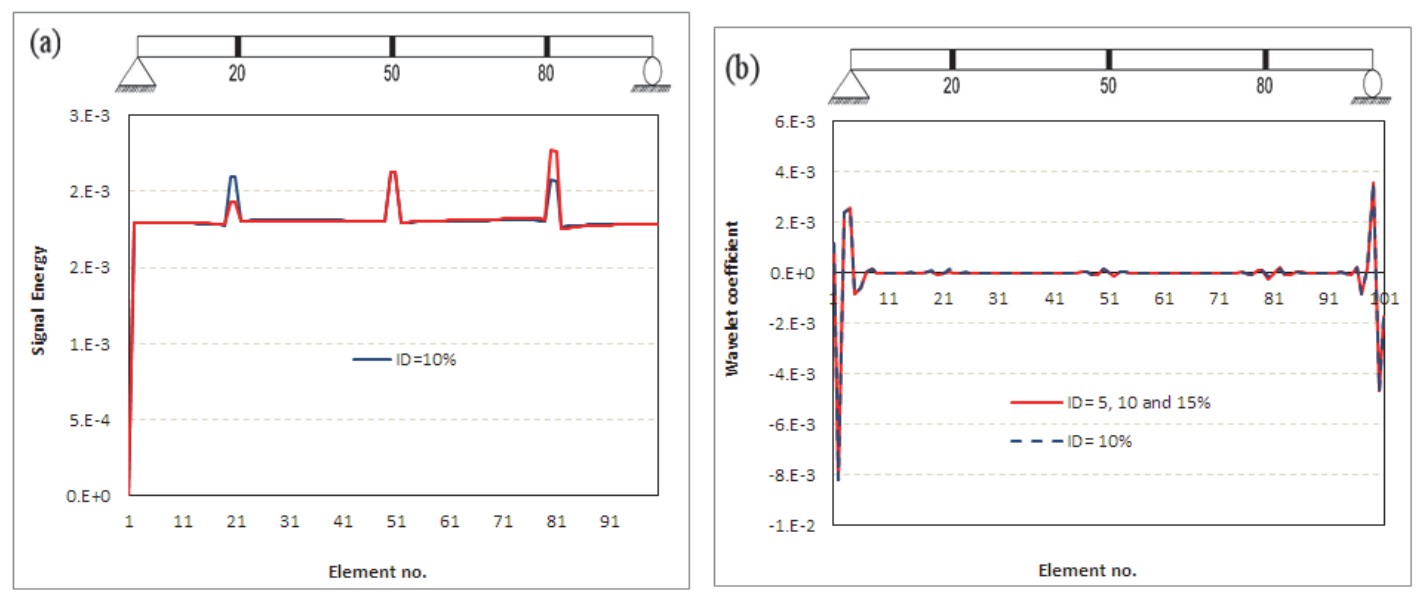

Figure 5: Damage detection using signal energy for scenario no.5 (a) and scenario no.6. (b).

Fig. 6 (graphs a,c) shows that the wavelet transforms for clamped-clamped boundary conditions in contrast with pinedpined supports, have better performance even for damaged elements with $5 \%$ intensity deficiency. Therefore, for such boundary conditions of the beams, the wavelet coefficients are relatively able to detect the local damages.

As can be seen from Fig. 6-c, when the damaged elements are close to each other, a significant disturbance appears in the vicinity of the damaged elements. In the clamped-clamped beams, when the damages are near the supports, because of the existence of disorders due to the supports, the wavelet coefficients are not able to detect the damages and extension of the mode shapes could not resolve this deficiency (graph a). Graphs b, d in Fig. 6 reveal that signal energy is successful in detecting damages in clamped-clamped beams. However, it should be noted that mode shapes in this type of beams are not a sinusoidal form, and the energy of mode shapes is not constant but had a curved form. In such a situation, if the damaged 
elements are near the supports, the curvature and the value of energy are negligible, and as a result, the detection process is not easy.

Fig. 7 displays damage identification for a beam with a spread-configuration of damage using the prescribed methods. As can be seen from this figure, the wavelet doesn't show acceptable performance even for this damage configuration. Oppositely, signal energy is able to detect the spread of damages very well.
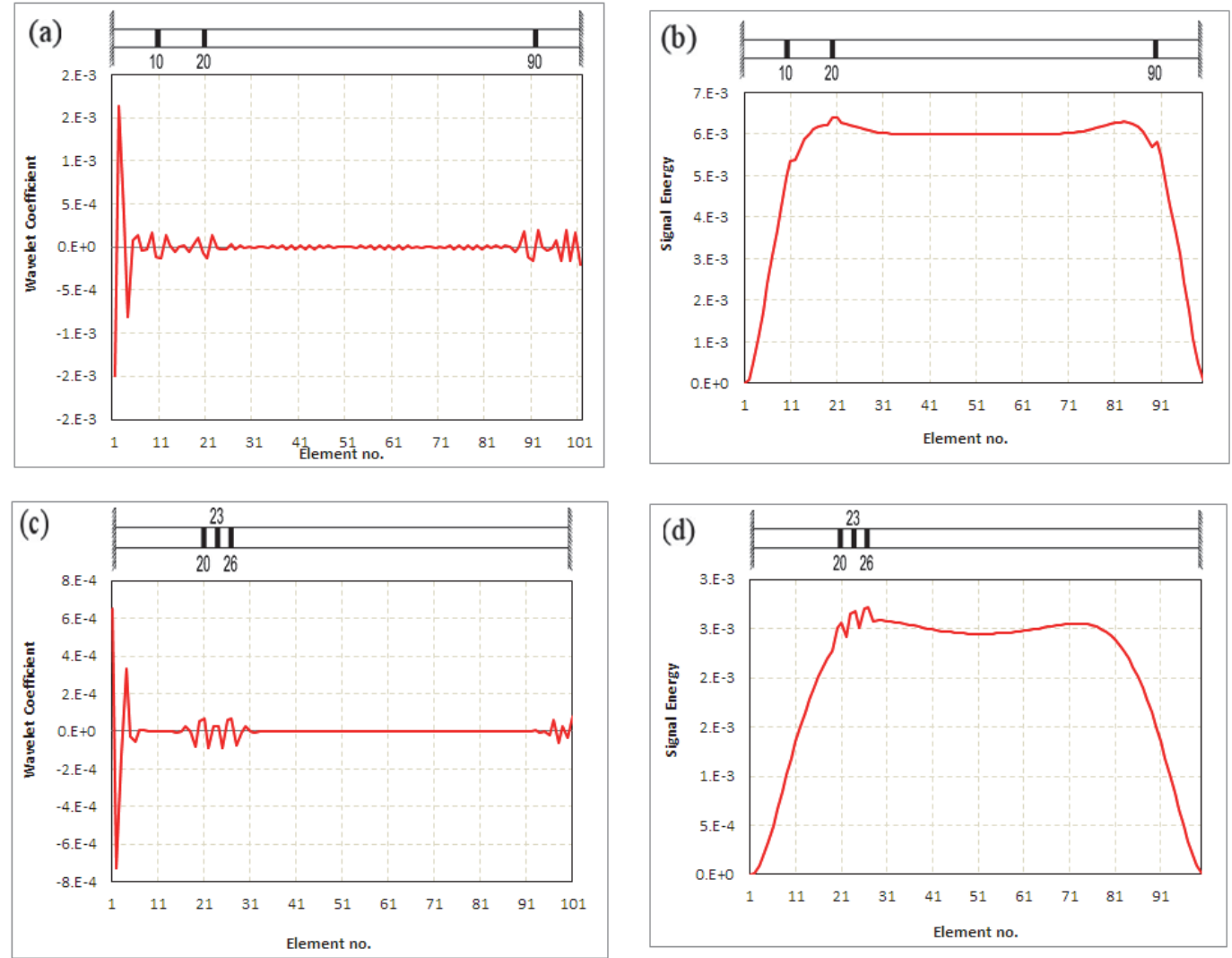

Figure 6: Damage detection: wavelet transform for scenario no. 7 (a), signal energy for scenario no.7 (b), wavelet transform for scenario no. 8 (c) and signal energy for scenario no.8 (d)
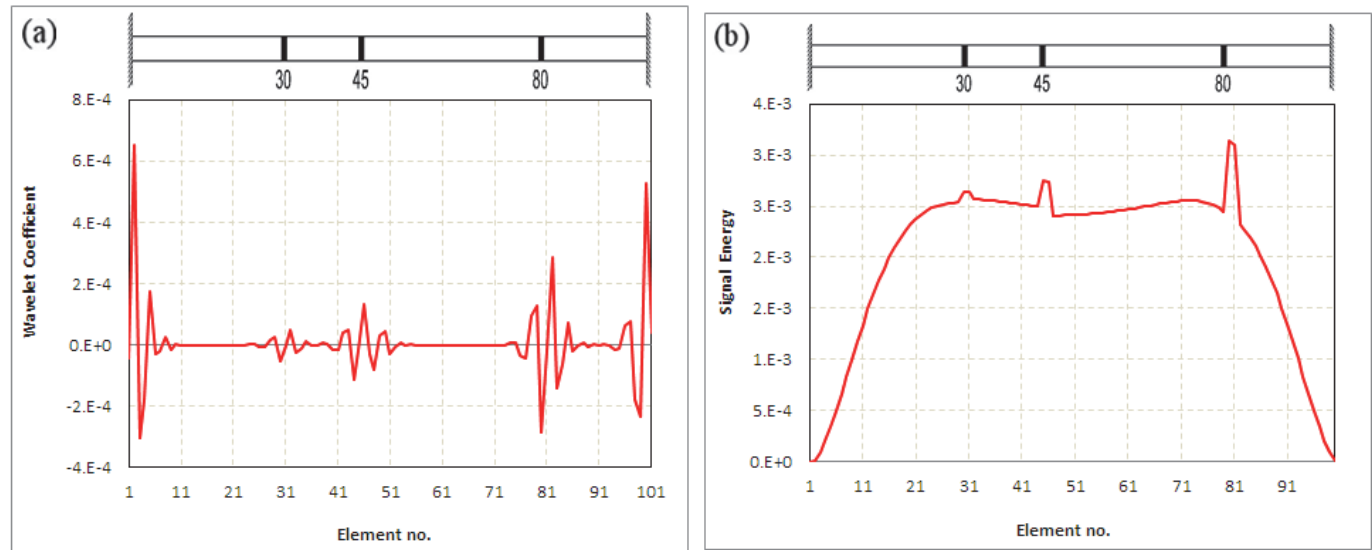

Figure 7: Damage detection using wavelet transform for scenario 9 (a), and signal energy for scenario 9 (b)

\section{Results in noisy conditions}

When the noise is added to the mode shapes, the damage detection procedure will be influenced by the added noise. For this purpose, using the following function in MATLAB, the noisy data are produced. 


$$
\mathrm{y}_{\mathrm{n}}=\operatorname{awgn}\left(\mathrm{y}_{0}, \mathrm{SNR}\right)
$$

where $\mathrm{y}_{\mathrm{n}}, \mathrm{y}_{0}$ are the output signal as a contaminated mode shape and the input signal as a clean mode shape, respectively. In order to simulate the noisy conditions for mode shapes, the scenarios listed in Tab. 3 have been taken into account. In all scenarios, the damage intensities are $5 \%$.

\begin{tabular}{ccccc}
\hline $\begin{array}{c}\text { Scenario } \\
\text { no. }\end{array}$ & $\begin{array}{c}\text { Support } \\
\text { condition }\end{array}$ & $\begin{array}{c}\text { No. of } \\
\text { damaged } \\
\text { elements }\end{array}$ & SNR $(\%)$ & $\begin{array}{c}\text { Order of mode } \\
\text { shape in } \\
\text { wavelet and } \\
\text { signal energy }\end{array}$ \\
10 & Pined-Pined & 10,50 & 75 & 1 \\
11 & Pined-Pined & 10,50 & 75 & 5 \\
12 & Clamped-Clamped & 28,72 & 75 & 2 \\
13 & Clamped-Clamped & 28,72 & 75 & 5 \\
14 & Pined-Pined & 20,80 & 65 & 3 \\
15 & Clamped-Clamped & 28,72 & 65 & 5 \\
16 & Clamped-Clamped & 28,72 & 55 & 6 \\
\hline
\end{tabular}

Table 3: The scenarios for damage detection in noisy conditions.
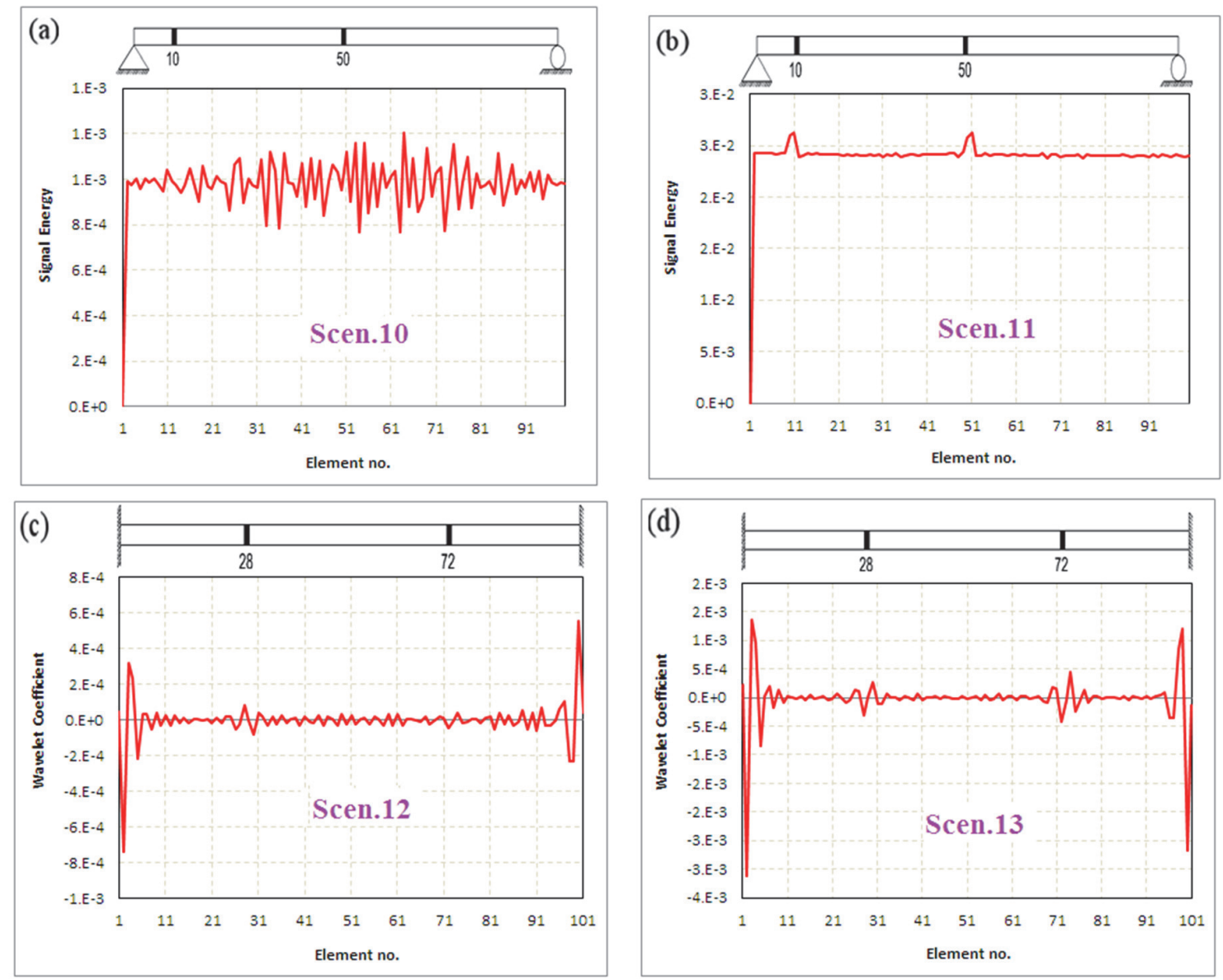

Figure 8: Damage detection using signal energy and wavelet transform in scenarios 10 (a) to 13 (d).

When the $\mathrm{SNR}=75 \%$ is added to the responses, modal curvatures from lower mode shapes are distorted, and both wavelet coefficients and energy signal methods required employing the higher mode shapes, namely higher than the $5^{\text {th }}$ mode. As noted before, the applied wavelet transform does not represent an appropriate performance in the detection of low- 
intensities in pined-pined beams. It turns out that in the noisy condition ( $\mathrm{SNR}=75 \%$ ) wavelet transform could not detect damages even using higher modes. However, in clamped-clamped beams, the wavelet transform can detect the damages using $5^{\text {th }}$ mode shape data.

Fig. 8 presents the damage detection for scenarios 10 to 13 in noisy conditions. In scenario no.10, when the lower mode shape data is used, the detection is impossible, and employing the higher modes is needed. In scenario 11 , the $5^{\text {th }}$ mode shape information for damage detection is employed, and detection is clear. In opposite to the signal energy technique, the use of high and low mode shapes in the wavelet transform method doesn't lead to significant improvement (graphs c, d).

When the values of SNR are reduced, both wavelet transform and energy signal methods could not detect the damages even after applying of the $5^{\text {th }}$ and $6^{\text {th }}$ order of the mode shapes. In this paper, to solve this problem, a combination of discrete wavelet and signal energy methods has been employed. For detection of damages, firstly, a discrete wavelet is applied on the curvature of the mode shape as a noisy response and then approximate and detail wavelet coefficients have been extracted using Eqn.(4). Because the signal is noisy, the coefficients are not able to detect the locations of the damaged elements, and the appeared disorders in the damaged elements have been affected by the noise. Nevertheless, by applying the signal energy operator in approximate wavelet, damage detection successfully has been obtained.

Fig. 9, displays the locations of damaged elements in $\mathrm{SNR}=65 \%$. As can be seen from this figure, signal energy and wavelet transform individually are not able to detect the damaged elements. As can be seen from graph d, the combination of the proposed method has enough capability to identify the damages. However, near the supports, undesirable irregularities are clearly observed.
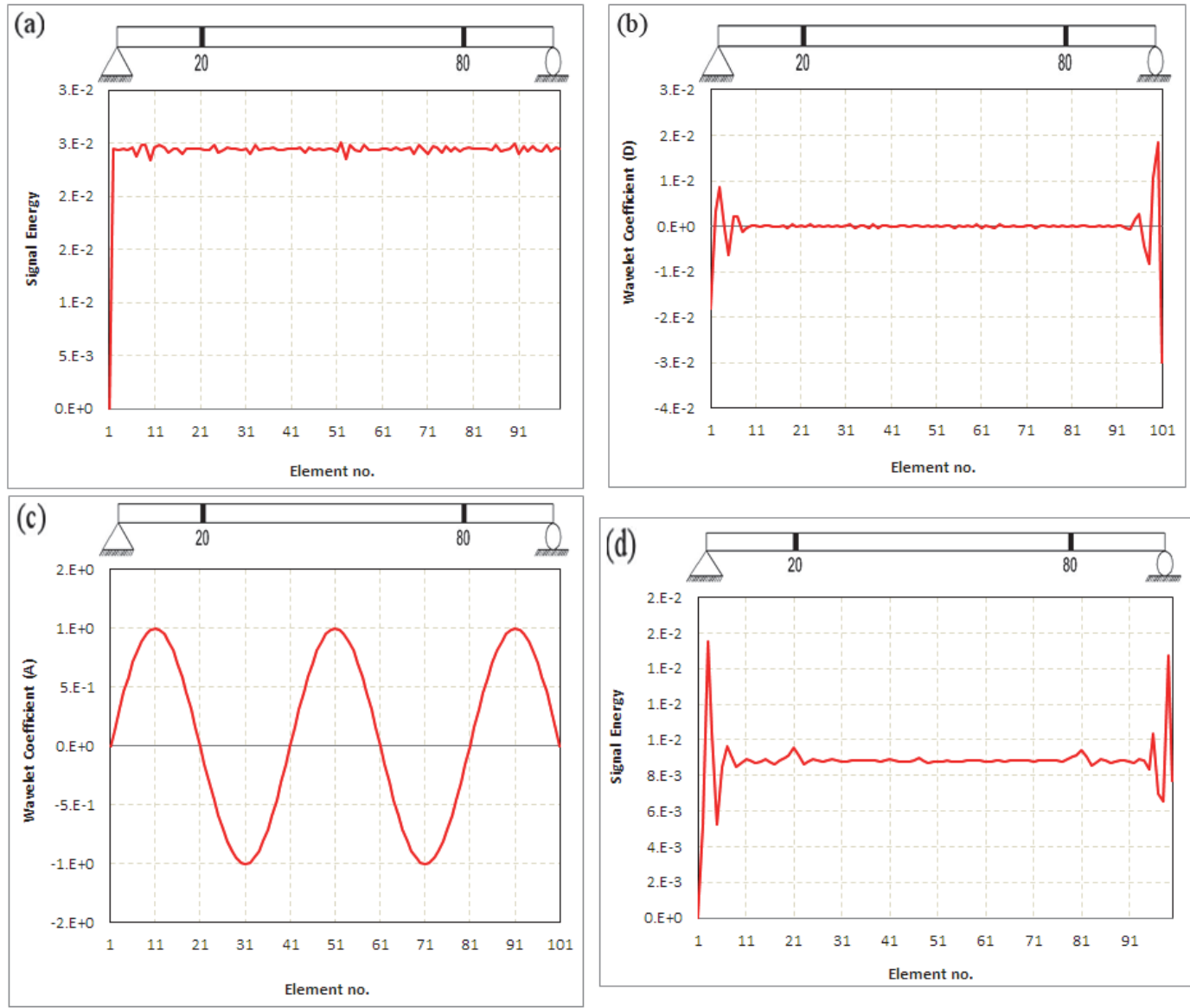

Figure 9: Damage detection for scenario no.14 using: only signal energy operator (a), wavelet coefficient detail (b), wavelet coefficient approximate (c) combination of wavelet and signal energy (d).

Fig. 10, illustrates the identification of damaged elements for $\mathrm{SNR}=65 \%$ and $55 \%$. As seen from this figure, the combination of signal energy and wavelet transforms methods could successfully detect the damaged elements. 

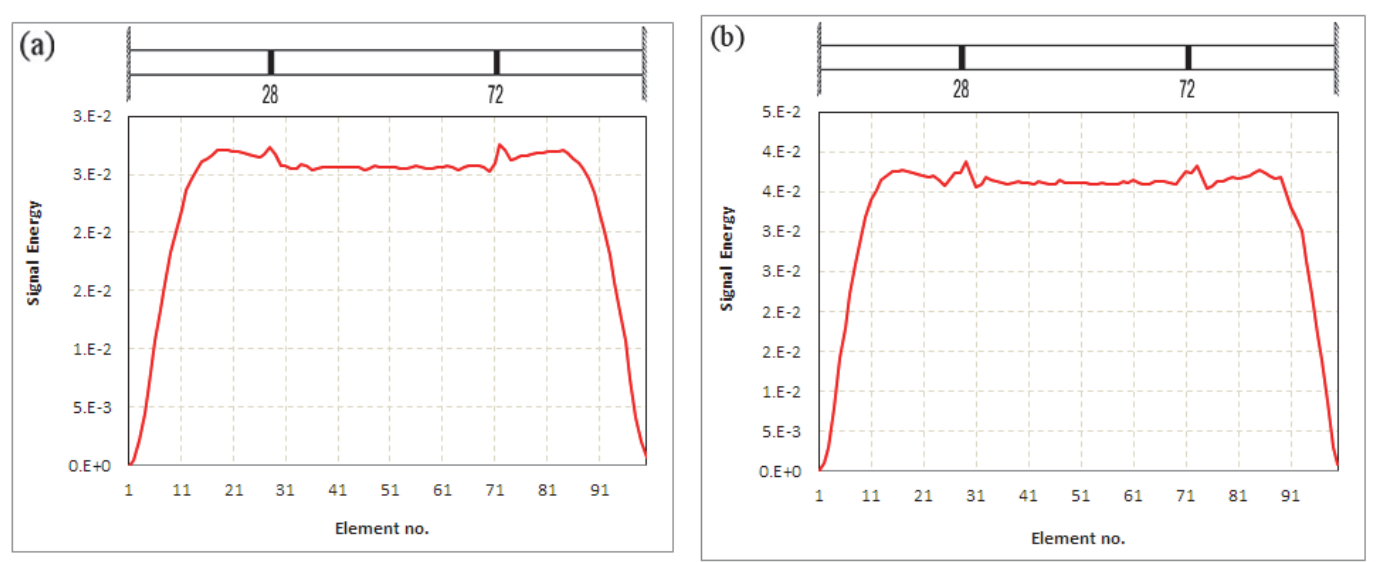

Figure 10: Damage detection using signal energy for scenarios 15 or $\mathrm{SNR}=65 \%$ (a), and for scenario no.16 or $\mathrm{SNR}=55 \%$ (b).

\section{CONCLUSIONS}

7 his paper utilizes the discrete wavelet transforms and Teager energy operator methods for damage detection for noisy and clean data. The results show the superiority of the signal energy in comparison with wavelet coefficients.

Moreover, the results confirm that each individual method in noisy conditions is not suitable for the detection of damages, but the combination of them has a great performance. Based on this investigation for the mentioned wavelet transforms and scenarios, the following conclusions could be drawn.

1- The signal energy method is able to detect damage using the $1^{\text {st }}$ and the $2^{\text {nd }}$ mode shapes with a $5 \%$ intensity in clampedclamped beams. However, when the cracks are in the vicinity of the supports, the higher mode shape, e.g. the $6^{\text {th }}$ mode shape or higher than it is needed. Wavelet transforms in the detection of damages with low intensities have poor performance in pined-pined beams. Moreover, for the detection of crack close to the support by means of wavelet transforms, the extension of the mode shape from both sides is required. Therefore, this problem makes detection difficult. 2- For clamped-clamped beams, signal energy has enough capabilities to detect damage using the first mode shape for low intensities. However, when the detection of damage is required near the supports, the higher mode shape data should be taken into account. Wavelet transforms have better performance for clamped-clamped beams, compared to the pined-pined ones. However, when the cracks are near the supports, this method is inefficient.

3- The sensitivity of signal energy is higher for all intensities of damages while wavelet transforms are insufficiently sensitive to various intensities. Therefore, in practice applying the energy method is recommended. When the value of SNR is equal to $75 \%$, the signal energy method with higher mode shapes data can detect even low damages, while lower mode shapes are affected with noise, and detection is impossible. Wavelet transforms at noisy conditions could not detect the damages at pined-pined beams. When the values of SNR are reduced to $65 \%$ or $55 \%$, even the signal energy method could not detect the damaged elements. In these cases, the combination of energy and wavelet is required for proper flaw detection. Nonetheless, using the higher mode shapes is strongly recommended.

\section{ACKNOWLEDGMENT}

he first author acknowledges the support of Malayer University when he was an assistant professor of civil engineering from September 2008 to June 2019.

\section{DisCLOSURE}

he authors have no conflict of interest to declare. 


\section{REFERENCES}

[1] Doebling, S. W., Farrar, C. R., Prime, M. B., and Shevitz, D. W. (1996). Damage identification and health monitoring of structural and mechanical systems from changes in their vibration characteristics: a literature review (No. LA-13070-MS). Los Alamos National Lab., NM (United States).

[2] Ratcliffe, C. P. (1997). Damage detection using a modified Laplacian operator on mode shape data. Journal of Sound and Vibration, 204(3), pp. 505-517.

[3] Wang, Q., and Deng, X. (1999). Damage detection with spatial wavelets. International journal of solids and structures, 36(23), pp. 3443-3468.

[4] Hou, Z., Noori, M., and Amand, R. S. (2000). Wavelet-based approach for structural damage detection. Journal of Engineering Mechanics, 126(7), pp. 677-683.

[5] Chang, C. C., and Chen, L. W. (2003). Vibration damage detection of a Timoshenko beam by spatial wavelet based approach. Applied Acoustics, 64(12), pp. 1217-1240.

[6] Ovanesova, A. V., and Suarez, L. E. (2004). Applications of wavelet transforms to damage detection in frame structures. Engineering structures, 26(1), pp. 39-49.

[7] Loutridis, S., Douka, E., and Trochidis, A. (2004). Crack identification in double-cracked beams using wavelet analysis. Journal of sound and vibration, 277(4-5), pp. 1025-1039.

[8] Chang, C. C., and Chen, L. W. (2005). Detection of the location and size of cracks in the multiple cracked beam by spatial wavelet based approach. Mechanical Systems and Signal Processing, 19(1), pp. 139-155.

[9] Gökdağ, H., and Kopmaz, O. (2009). A new damage detection approach for beam-type structures based on the combination of continuous and discrete wavelet transforms. Journal of Sound and Vibration, 324(3-5), pp. 1158-1180.

[10]Rucka, M. (2011). Damage detection in beams using wavelet transform on higher vibration modes. Journal of theoretical and applied mechanics, 49(2), pp. 399-417.

[11]Zhong, S., and Oyadiji, S. O. (2011). Detection of cracks in simply-supported beams by continuous wavelet transform of reconstructed modal data. Computers and structures, 89(1-2), pp. 127-148.

[12]Zhong, S., and Oyadiji, S. O. (2011). Crack detection in simply supported beams using stationary wavelet transform of modal data. Structural Control and Health Monitoring, 18(2), pp. 169-190.

[13]Algaba, M., Solís, M., and Galvín, P. (2012). Wavelet based mode shape analysis for damage detection. In Topics in Modal Analysis II, Springer, New York, NY., 6, pp. 377-384.

[14]Solís, M., Algaba, M., and Galvín, P. (2013). Continuous wavelet analysis of mode shapes differences for damage detection. Mechanical Systems and Signal Processing, 40(2), pp. 645-666.

[15]Khorram, A., Rezaeian, M., and Bakhtiari-Nejad, F. (2013). Multiple cracks detection in a beam subjected to a moving load using wavelet analysis combined with factorial design. European Journal of MechanicsA/Solids, 40, pp. 97-113.

[16]Cao, M., Radzieński, M., Xu, W., and Ostachowicz, W. (2014). Identification of multiple damage in beams based on robust curvature mode shapes. Mechanical Systems and Signal Processing, 46(2), pp. 468-480.

[17]Cao, M., Xu, W., Ostachowicz, W., and Su, Z. (2014). Damage identification for beams in noisy conditions based on Teager energy operator-wavelet transform modal curvature. Journal of Sound and Vibration, 333(6), pp. 1543-1553.

[18]Akbari.J, Ahmadifarid.M (2018), Damage Detection of frames using Wavelet Transforms and Signal Energy, 7th National and 3rd International Conference on Modern Materials and Structures in Civil Engineering, BuAli Sina University, Hamedan, Iran, September 8-9.

[19]MATLAB (2018), The MathWorks, Inc., Natick, Release 2018a

[20]Blatter, C. (2018). Wavelets: a primer. AK Peters/CRC Press. 